Journal of Social and Development Sciences

Vol. 3, No. 8, pp. 286-292, Aug 2012 (ISSN 2221-1152)

\title{
The Global Economic Crisis and its Effects in Romania
}

\author{
${ }^{1}$ Alexandru Trifu*, ${ }^{2}$ Radu Tasca \\ ${ }^{1}$ Petre Andrei University Iasi, Romania \\ ${ }^{2}$ Romanian Banking Institute Bucharest, Romania \\ *trifu.alex@gmail.com
}

\begin{abstract}
The crises represent malfunctions that may occur within every domain of the human activity. That is why the causes, their way of emergence and their consequences are studied. The crisis is analyzed by economists considering specific criteria, these offering it the characteristics of a phenomenon with poisonously consequences for the affected organizations, institutions and social groups: inflation, unemployment, stagnation, recession etc. The evolution of the financial crisis will lead economies into a deflationary spiral in the next year or even a longer lasting, as deficit reduction efforts will take large, and probably we shall assist an output of some euro area of weaker states. World economies are hit by this crisis to various extents, depending on the vulnerabilities of each and their exposure to toxic assets. The response to the crisis is contingent upon the fundamental principles we believe in, the available resources, the institutions and the instruments we can make use of. In Romania, the response to the adverse effects of the crisis cannot be similar to that made by some European countries or the U.S. There are several differences between the Romanian economy and these economies, which do not allow copying the package of measures developed there.
\end{abstract}

Keywords: financial crisis effects, economic policy, economic growth, euro zone, Romanian economic crisis

\section{Introduction}

A real financial crisis has as characteristic the fact that a specific local accident has the capacity to propagate to the level of the entire financial system. According to economic specialty literature (Fischer et al., 1999), the financial crisis is a phenomenon, which is in the spotlight of worldwide economists because of the impact on their economies. Specialists of every country try to find solutions for overcoming the economic crisis by adopting an optimal combination of all policies: budgetary, salary, monetary in order to move the business towards work and productivity. Even if the ongoing economic adjustment process cannot be accurately planned, however, the promotion of the coherent and credible economic policies could avoid a disorderly adjustment (hard landing).

Defining the crisis concept: In our evolution, the crises (Nita, 1999) can be defined as situations characterized by a severe instability, thus being characterized by a rising volatility and uncertainty. In crises (regardless of its form), we are in a constant estate of anxiety and insecurity concerning the future, fear or even panic. Our defensive and conservation instinct urges us to sometimes irrationally behave and to more accentuate this volatility because each one of us, with the cognitive capacity we possess we filter the information and understand the phenomenon in our own way, translating it in a certain market related behavior. The problem in defining these crises is the measurement of how high the volatility or decrease of the markets should be in order to classify such an evolution as a crisis; how high a certain country's inflation, unemployment or GDP decrease should be in order to state that the country entered a crisis (Angelescu et al.,, 1999). Conventionally, it was settled that recession is considered when, after two successive quarters, one has to deal with a country or region's GDP decrease. National Bureau of Economic Research (NBER) defines the crisis as being "a significant decrease of the economic activity for several months, reflected by the GDP decrease, individual income decrease, employment level reduction, industrial production and consumption diminishing. There are some specialists that classify these crises as social crises (increasing inflation, unemployment, poverty), in financial crises (steep volatility on the capital markets, stock markets falling and spectacular comeback), political crises (possibly degenerating to wars), local or international crises caused by natural disasters or generalized economic crises. It is difficult to consider the moment when a financial crisis 
becomes an economic one or if an economic crisis causes a financial one or vice-versa. The stock exchange is the economy's barometer and it deals businesses of various sizes and from different sectors. When these businesses' markets (real estate market, oil market, labor market) suffer malfunctions or major corrections, they will be reflected in the profitability of the listed companies and, therefore, in the price of the stocks (shares or bonds) that directly depend upon the investors' expectations.

The dimensions of the crisis: On the financial crisis' dimension - Jacques Attali (French politics analyst) considered the global banking system as bankrupted. He offers some significant figures:

- The total of the toxic assets in the world is 14000 billion dollars, which 3800 with no value $(1 / 2$ in USA; $1 / 2$ in Europe);

- The total of global banking lending: 80000 billion dollars;

- The banks' own funds (equity) sum only 2000 billion dollars.

This amplification of some virtual values' circulation, without covering in the real economy and in the financial support of the banks (and other lending systems) seems like the well-known mechanism of the Ponzi schemes. That is why the banks stopped the lending and are searching to rebuild their own funds. The result was triggering an infernal spiral:

- The lack of banking loans

- Investments stoppage

- Productive activities' reduction

- Unemployment increase

- Purchasing power and commercial activities' decrease

This made the process triggered as a crisis of the financial system to transform into a global depression, comparable to the 1929-1933 one. Additional, there is a disparity between the democracy and the markets: the former is a human invention, created in order to pacify the relations between people; the latter is the spontaneous expression of the way our species solves the problems in wilderness, when everybody fights everyone. The balance in competition universe is ensured only by the strict control conditions. Any weakening of the control leads to the strong eliminating the weak, the former sharing their domination areas in order to impose their conditions. Concerning the governments' measures taken until now, it is considered that these only pursued the banks' salvage, circumventing the crisis's size and consequences (Ackermann, 2008). Injecting financial resources in banks does not at all affect their power and freedom. Therefore, the conclusion is that it is impossible to have the finances to the service of the real economy, of industry and people.

\section{The evolution of the financial crisis}

The evolution of the financial crisis will lead developed economies towards a deflationary spiral in the next year or even for a longer period, as deficit reduction efforts will take large, and probably we shall assist to the withdrawal of some weaker states from the euro area. The growth in U.S. and the euro area was based largely on the consumption and debt over the last two, three decades and every time the economy has tried to eliminate the excesses and errors resulting from excessive growth of the credit, the interest rates were low and the debt burden became even greater, notes the analyst. This type of model succeeds on a short term, but in time needs more and more substantial stimulants as to avoid a collapse. This evolution was facilitated by an irresponsible approach of the debt and speculation problem, evident in the ease with which they were saved from insolvency imprudent countries and private companies from Mexico and countries from the Southeast Asia to the fund Long Term Capital Management in 1998. This has contributed to an overall increase in debt burden, accumulated during the credits offered too cheaply. "And now it would be too simplistic and naïve, for the West to believe that can easily escape the sins of excess crediting in the past 20 years. In the euro zone, we could witness the secession of some of the weakest members, which is probably the desire of Germany, as suggested by the German analyst Wolfgang Munch.

The concept of fiscal economic policy: The concept of fiscal policy is often presented with different nuances, usually highlighting its tax system promoted by a certain state (Dolgu, 2009). In fact, the fiscal policy 
can be perceived only as a mix between the ways of procuring the state's disposal resources and the ones regarding the given destinations in order to fulfill its functions and duties. The European policy in taxation field has two large components: direct taxation - which is the responsibility of the member states and indirect taxation that affects the free circulation of the goods and services. The member states have already taken measures in order to prevent the tax evasion and the double taxation, and the European policy of this field has as main purpose to ensure on the internal market that the competition is not being distortional due to the differences between the indirect taxation systems and rates. In addition, measures have been taken in order to prevent the negative effects of the competition in the taxation field that might occur during the funds' transfers between the European Union's member states.

\section{The levels of approach}

The benchmark fiscal levels:

- Local and national framework

- International framework

The local framework: the right to establish tax is limited, because by fiscal pressure one has the pursuit of avoiding the population focus on certain areas of fiscal reasons. The fiscal policy also considers the mitigation of socio-economic differences between different areas. The modern fiscal theory considers that horizontal balance between collective entities must be ensured, and the right of public administrations to impose taxes must be limited.

\section{The national framework targets:}

- The cost of taxation administration;

- The option of each country's government to choose the imposing criteria, the imposing techniques.

- The tax redistributing between different levels of public administration, without creating distortions among its different levels and without affecting their degree of financial autonomy.

\section{The international framework}

- The interdependency between the national fiscal pressures

- The emergence of double legal imposing

- Avoiding the double international legal imposing is based upon fiscal decisions

- The existence of fiscal paradises, as mainly an exogenous factor, which causes decisions for measures of avoiding and discouraging the international tax evasion.

The structural fiscal decisions of harmonizing the fiscal policies are subject to restrictions caused by the existing differences between countries. The fiscal policy is influenced by the conditions that have to be met in order to be accepted in the respective unions. At EU level, the fiscal policy is subordinated to the treaty of establishing the European Community, which agrees to:

- Eliminating the custom taxes between the member countries and any other measures with similar effects;

- Ensuring the free competition within the Euromarkets ("common market").

To this extent, mainly the indirect taxes are taken into consideration (VAT and excises); direct taxes only being subordinated to the purpose of not affecting the free competition on the market, yet signing conventions of avoiding the double international imposing are being recommended to the members. Additionally, the Maastricht treaty (1992) imposes to the Monetary Union members the limitation of the budgetary deficits to 3\% of GDP and a maximum public debt of $60 \%$ of GDP, recommending the Monetary Union non-participating members to avoid substantial deficits. However, both convergence criteria were not met, fact that can be observed in the tables below:

The last century was characterized, in Western Europe, by the expansion of the public sector's role, by the 
economic and fiscal regulations (Trifu, 2005). The EU countries did not maintain the level of public expenditure to approximately $60 \%$ of GDP, as it can be seen in the table below:

Table 1: The evolution of the budgetary deficit 2005-2010 in EU countries (European Commission, 2011)

\begin{tabular}{llllllll}
\hline No. & Country/Year & $\mathbf{2 0 0 5}$ & $\mathbf{2 0 0 6}$ & $\mathbf{2 0 0 7}$ & $\mathbf{2 0 0 8}$ & $\mathbf{2 0 0 9}$ & $\mathbf{2 0 1 0}$ \\
\hline 1 & Belgium & -0.2 & -0.6 & -1.6 & -2.2 & -4.0 & -3.3 \\
2 & Germany & -2.4 & -1.4 & -0.6 & -0.3 & -0.9 & -2.4 \\
3 & Estonia & 1.2 & 1.0 & -1.3 & -4.0 & -0.2 & -0.1 \\
4 & Ireland & 1.3 & 2.9 & -1.7 & -7.3 & -9.8 & -9.7 \\
5 & Greece & -5.7 & -3.7 & -7.5 & -9.7 & -14.2 & -9.0 \\
6 & Spain & 1.2 & 2.0 & 1.3 & -3.9 & -8.6 & -7.0 \\
7 & France & -3.6 & -2.7 & -3.8 & -3.6 & -5.8 & -5.7 \\
8 & Italy & -4.5 & -2.8 & -3.1 & -3.5 & -4.1 & -3.5 \\
9 & Cyprus & -2.8 & -0.7 & 2.5 & -0.3 & -5.7 & -5.7 \\
10 & Luxemburg & 0.4 & 1.4 & 1.7 & 2.3 & 1.7 & 0.3 \\
11 & Malta & -3.8 & -2.9 & -3.0 & -5.3 & -3.5 & -4.3 \\
12 & Holland & 0.8 & 1.1 & -0.8 & -0.3 & -3.4 & -3.5 \\
13 & Austria & -0.8 & -1.4 & -1.6 & -1.8 & -2.3 & -3.2 \\
14 & Portugal & -5.2 & -3.2 & -3.2 & -3.8 & -8.0 & -9.6 \\
15 & Slovenia & -0.9 & -1.3 & -3.0 & -5.0 & -3.9 & -3.9 \\
16 & Slovakia & -1.0 & -3.1 & -3.5 & -4.2 & -7.5 & -7.5 \\
17 & Finland & 3.7 & 4.2 & 2.4 & 2.4 & 0.6 & -0.9 \\
& EURO AREA & & & & & & \\
18 & Bulgaria & 1.5 & 2.5 & 2.8 & -0.1 & -3.6 & -1.4 \\
19 & Check Rep. & -3.3 & -2.9 & -3.0 & -4.6 & -5.4 & -4.6 \\
20 & Denmark & 5.3 & 4.1 & 3.1 & 3.1 & 0.9 & -0.1 \\
21 & Lithuania & -1.1 & -1.0 & -3.0 & -5.5 & -7.4 & -5.0 \\
22 & Latvia & -0.5 & -1.1 & -4.4 & -6.2 & -7.8 & -4.6 \\
23 & Hungary & -8.6 & -9.7 & -5.6 & -4.6 & -2.2 & -3.8 \\
24 & Poland & -4.2 & -4.0 & -3.1 & -4.8 & -7.3 & -7.6 \\
25 & Romania & -1.6 & -2.7 & -5.0 & -8.4 & -9.0 & -6.1 \\
26 & Sweden & 1.9 & 1.5 & 1.1 & 0.9 & 2.0 & 1.3 \\
27 & UK & -3.4 & -2.8 & -3.7 & -4.7 & -8.7 & -8.9 \\
\hline
\end{tabular}

The ones that heavily overcome this level were Greece, Ireland, Portugal, Italy and even Germany. These have partially financed the classic public goods, such as national defense. Yet, the most important part of the public expenditure increase is due to the expansion of the state's redistribution function (by social welfare). This considers the public pension and health system which generates the most important transfers between generations and within: transfers of financial resources from the active labor towards the unemployed, towards unqualified employed, students, families with children, towards agricultures, towards the employees of certain industrial branches characterized by harsh working environment (such as naval constructions or mining), towards the inhabitants or even the entrepreneurs from the least favored area or towards other social categories. From a fiscal point of view, the public expenditure was financed by the consumption taxation (indirect taxes), the taxation of both wages, as well as companies' profits. This taxation structure in Europe moves the weighting centre towards the households that consume largely, obtain important revenues and/or own important properties (Lipsey, et al., 1999). Of course, the European fiscal system differently affects the household or companies categories due to structural differences (such as revenues, consumption and owned properties), but also due to different degrees of regulation, different ways to manage the fiscal system branches and various possibilities to avoid taxation. Such characteristics of the fiscal systems also imply, along the directly targeted revenues redistribution processes, accidental redistributions. The financial 
crisis have obliged many governments in Europe to help some powerful banks by supporting their banking system with measures that consider the local and foreign currency fluidity, the deepening of the cooperation between banks, creating certain recapitalizing funds which will inject liquidities in banks and receiving help from International Monetary Fund and European Union. Additionally, the normal fluctuations of the markets could by amplified by the liquidity problems. A major cause of the liquidity risk is the recent spread of some complex financial instruments, such as the lending derivatives or structured products as certified bonds. Although a secondary market for these products exists, these instruments are based on quantitative models for relative value assessment, investment decisions and price setting. That is way there is the risk that similar model would determine the investors to exit the market the same time, thus causing a lack of liquidities, and this even more as the speculative positions have been encouraged by the low interest rates and the relative stability of the markets (IMF, 2011).

Table 2: The evolution of the public debt 2005-2010

\begin{tabular}{lllllll}
\hline Country/Year & $\mathbf{2 0 0 5}$ & $\mathbf{2 0 0 6}$ & $\mathbf{2 0 0 7}$ & $\mathbf{2 0 0 8}$ & $\mathbf{2 0 0 9}$ & $\mathbf{2 0 1 0}$ \\
\hline Belgium & 92.1 & 88.1 & 84.2 & 89.6 & 96.2 & 96.2 \\
Germany & 68.0 & 67.6 & 64.9 & 66.3 & 73.4 & 83.2 \\
Ireland & 27.4 & 24.8 & 25.0 & 44.3 & 65.5 & 94.9 \\
Greece & 100.3 & 106.1 & 105.0 & 110.3 & 126.8 & 144.9 \\
France & 66.4 & 63.7 & 63.8 & 67.5 & 78.1 & 82.3 \\
Italy & 105.8 & 106.6 & 103.6 & 106.3 & 116.0 & 118.4 \\
Portugal & 61.7 & 63.9 & 62.7 & 65.3 & 76.1 & 93.3 \\
EURO AREA & 70.0 & 68.4 & 66.0 & 69.7 & 79.1 & 85.6 \\
UK & 42.5 & 43.4 & 44.5 & 52.1 & 68.2 & 79.9 \\
EU & 62.7 & 61.5 & 58.8 & 61.8 & 74.0 & 80.3 \\
USA & - & - & 62.4 & 71.5 & 84.7 & - \\
Japan & - & - & 187.7 & 194.7 & 213.9 & - \\
\hline
\end{tabular}

The macroeconomic context of the economic crisis appearance in 2009-2011: The effects of the international financial crisis have also spread on the Romanian economy. However, the banking system was less affected by not being exposed to the toxic assets, and because of prudential and administrative measures adopted in time by the National Bank of Romania. The international financial crisis and especially its obvious consequence the recession in the developed countries - are expanding on the Romanian economy on multiple channels. On the commercial the channel, slows or even reduces the export growth. On the financial channel, limits the access to the external financing, and thus restrict, the volume of lending, and creates difficulties in the private external debt service. On the exchange rate channel, reducing the external financing reflected in the national currency depreciation. On the confidence channel, there was a withdrawal of investors from the Eastern Europe countries. This as the effect the manifestation on the monetary currency market of some moments of panic and speculative attacks, such as the one in October 2009 in Romania, which made necessary the intervention of NBR, the central bank (Popa, 2009). Finally, on the channel of wealth and balance sheet effects, the damage of the net assets of people and the companies occurs, due to the high proportion of loans in the foreign currency (related to the national currency depreciation) and the drop of the asset prices and capital values at unsustainable values (the propagation of these effects determines that the degree of uncertainty regarding the evolution of the economic variables be extremely high). This contributes, in its turn, to the accentuation of the crisis through the negative effects it has on the expectations and by increasing the degree of cautious consumers and traders. In essence, we talk about the fact that the Romanian economy has a large current account deficit, which indicates its dependence on the external financing. We have to choose between the orderly reductions of this deficit or its reduction by the market in the current conditions of tension and chose mistrust, with dramatic consequences for the exchange rate and the economic growth.

Even if the ongoing economic adjustment process cannot be accurately planned, however, the promotion of the coherent and credible economic policies could avoid a disorderly adjustment. Thus, the government should avoid an emotional crisis approach under the unions and employers pressure, which should lead to same measures to stimulate the intern demand, complicating the reduction of the current account deficit at a 
sustainable level. Only a concentration of the macroeconomic policies combination on the process of the adjusting external imbalances (the current account deficit) and of the internal one (the budget deficit) may lead to the support of the soft landing of the economy and to improving the perception of the foreign investors. Generally, financing agreements with the international organizations, starting with the European Commission and the European Investment Bank are needed; in order to compensate for the reduction of sensitive private capital inflows are welcome. As for the National Bank of Romania, it remains consequent in its economic growth projection for 2012, with the following arguments:

- lower share of exports in GDP compared to other Central and East European countries, which still have projected a positive growth in 2012;

- the low level of the financial intermediation (nongovernmental credit as a share of GDP), which implies a smaller contraction of the economy due to the financial channel;

- The exchange-rate flexibility, which allows some exogenous shocks to dissipate over the nominal variables (exchange rate), rather than to affect the real economy.

In the case of Romania (Fota \& Bacescu, 2009), despite the negligible effects of the crisis on the banking system of Romania due to the limited exposure to the toxic assets, the measures for promoting the recovery of lending through the recapitalization of banks could help the rebound of the consumption credit support and the prevention of a too long recession. The impact of the global crisis, which has contracted the external demand particularly, affects the real economy. Viewing the economy vulnerabilities caused by the accelerated deterioration of the current account in recent years mainly due to the growth of trade deficit, Romania's external financial position was on the edge of a crisis, which, in any way, would have rendered an external loan necessary to cover the financial gap.

\section{Conclusion}

In a world with great financial and currency crisis, the question is what can be done in order to prevent or at least reduce their effects. The issue of financial education is one of the things that European Commission believes that can help in the prevention of the future credit crisis, and this subject was on the agenda since the summer of 2007. The possibilities, highlighted by many economists, is that of coming back to the reality of the 60 's, when the capital was extensively controlled, which prevented the movement of massive fluctuations of capital or the emergence of financial innovations leading to crisis. Once the crisis is over, things will not come back to the way they were before, especially the banks' ways of doing business. Banks will have to return to a strong regulation and surveillance of credit market, such as careful examination of debtors' capacity of refunding the credits and a thorough evaluation of securities offered for investments will come back. The best defense against risk is a strong income source, able to offer an amortization against loss. Bank's basic capital is the one absorbing, eventually, all losses, but an excessive growth of subscribed capital demand during a liquidity crisis, may dry out once again the financial market. Another possibility would be for the countries to follow healthy and reliable policies, in order to avoid speculators' attacks. Many crises seem to be the obvious result of the incompatibility between internal policies and exchange rate system, which allows speculative attacks to occur. The cause discovered by empirical literature, particularly in the case of self-fulfilling currency crisis, is not so much what is done now, but what markets suspect will be done in the future.

\section{References}

Ackermann, J. (2008). The subprime crisis and its consequences. Journal of Financial Stability, 1(2). Angelescu, C., Stanescu, I. \& Gavrila, I. (1999). Economics, Oscar Print Publishing House, Bucharest.

Dolgu, G. H. (2009). The economic crisis. Finance. Theories. Selected studies, Expert Publishing House, Bucharest.

European Commission. (2011). Economic Forecast, Directorate-General for Economic and Financial Affairs, European Economy.

Fischer, S. T., Dornbusch, R. \& Schmalensee, R. (1999). Economics, second edition, McGraw-Hill Book Company, Singapore.

Fota, D. \& Băcescu, M. (2009). Economic crisis in 2009 in Romania. Causes, effects, solutions, Universitary Publishing House. 
IMF. (2011). Global Financial Stability Report: Responding to the Financial Crisis and Measuring Systemic Risks.

Lipsey, R., Chrystal, G. \& Alec, K. (1999). The positive Economy, Economics Publishing House, Bucharest.

Niţă, D. (1999). Economic Dictionary, Economics Publishing House, Bucharest.

Popa, A. (2009). Financial Crisis Effects on Romanian Economy, the Fourth International Conference on Economic Cybernetic Analysis: Global Crisis Effects on Developing Economies, A.E.S., Bucharest.

Trifu, A. (2005). The economic thought in space-time unit, Performantica Publishing House, Iasi.

www.bnr.ro

www.insse.ro 